\title{
BRITISH MEDICAL JOURNAL
}

LONDON SATURDAY JUNE 71958

\section{THE PROGNOSIS OF INFECTIVE HEPATITIS \\ A PRELIMINARY ACCOUNT OF A LONG-TERM FOLLOW-UP*}

BY

E. R. CULLINAN, M.D., F.R.C.P.

R. C. KING, M.D., M.R.C.P.

AND

J. S. RIVERS, M.B., B.Chir.

From St. Bartholomew's Hospital, London

It is generally agreed that the great majority of patients who suffer from acute infective hepatitis make a complete recovery with no lasting damage to the liver. The condition may, however, relapse or recur; in a small proportion of patients serious destruction of liver parenchyma occurs, resulting in acute or subacute hepatic necrosis, and, although the importance of uncomplicated infective hepatitis in the aetiology of portal cirrhosis is not clear, this must be considered as a possible long-term sequel to the acute attack. Even in the absence of such gross complications, return to perfect health is often delayed, while in a few patients symptoms may persist for long periods of time.

In considering these accepted facts it seemed that a long-term follow-up of a large sample of men who had suffered from infective hepatitis with jaundice in one of the four massive outbreaks of the disease which ravaged the armies massed around the Mediterranean shores in the second world war would provide a unique opportunity for assessing the morbidity and mortality of the acute attack and the incidence, character, and duration of subsequent ill-health, immediate and delayed, which sometimes followed. The first of these epidemics, which occurred in the autumn of 1942 among the land forces of the British Army at about the time of the Battle of El Alamein, was chosen, because one of us (E. R. C.) had had personal experience of it.

\section{The Initial Inquiry}

In the year 1949, with the co-operation of the War Office and the then consulting physician to the Army, Brigadier J. Bennett, and of the Ministry of Pensions, the medical records of a random sample of one of every five men who had had infective hepatitis in this epidemic seven years previously, from July 1,1942 , to June 30 , 1943, were studied. The vast majority referred to the second half of 1942, which was when the epidemic was at its peak. The sample numbered 1,465. From these were removed 78 who had been killed in action, four who had died at the time of the acute attack, six who had died from other causes, 60 who had had previous arsenical injections for the treatment of syphilis (and who might therefore have been suffering from inoculation hepatitis) or in whom there was doubt about the diagnosis, and 24 who were completely untraceable.

A personal letter containing a questionary was then written, and forwarded by Army Records Departments

*Presented at the World Congress of Gastroenterology, Washington, D.C., on May 28, 1958. to each of the remaining 1,293 men. The questionary was a simple one, and asked whether the man had felt $100 \%$ fit immediately after leaving hospital, and, if not, in what way and for how long. It also asked whether he had had any further attack of jaundice. We had $1,052(81.4 \%)$ replies, 1,030 of which were satisfactory.

\section{Clinical Features}

$85 \%$ of the men were between the ages of 18 and 30 years, and all were, of course, superbly fit. The disease ran its expected course, the onset being frequently preceded by an initial period of illness, characterized by anorexia, malaise, and sometimes fever and enlargement of the liver. A few days later the urine was seen to be dark and the patient jaundiced. Soon the appetite returned, followed by a sense of reasonable well-being. Then the urine became free from bile pigments and jaundice began to clear.

Approximately 70\% were in hospital between 6 and 25 days, while $60 \%$ of these were in from 11 to 20 days. Only $3.1 \%$ spent more than 50 days in hospital. Most of the men were transferred to a convalescent depot before returning to duty.

It is interesting that of the original sample of 1,465 men, 221 were officers and 1,244 were other ranks, a ratio of 1 to 5.6. This high number of officers bears out the observation that infective hepatitis as it occurred during the war around the Mediterranean Sea had a curious predilection for British Army officers. In this epidemic they were about $4 \frac{1}{2}$ times more likely than other ranks to develop the disease. Thus, the relative proportion of officers and other ranks affected in the Ninth Army was 4.6 to 1 (Cullinan, 1943), and in eleven regiments of the Eighth Army 4.7 to 1 (Spooner, 1944).

A second interesting feature of this epidemic was that it followed the forefront of battle. The brunt fell on the Eighth Army, which was in the Western Desert up to El Alamein, and heaviest of all on its front-line troops (Spooner, 1943). Thirdly, the gravity of the epidemic lay not so much in the numbers of men affected as in the length of time they were off duty. During the six winter months of 1942-3 infective hepatitis cost the British troops in the Middle East over half a million man-days in hospital.

\section{Mortality}

Among the 1,405 accepted cases of infective hepatitis ( 60 excluded because of syphilis or diagnosis in doubt) only 4 deaths occurred during the acute attack-a mortality of $0.28 \%$. One officer and three other ranks, all in their 
twenties, died of acute hepatic necrosis $2,6,12$, and 28 days respectively after the onset of symptoms.

\section{Recurrence}

It is well known that some patients have a recrudescence of symptoms while still in hospital. One observer put it as high as $15 \%$ (Wilson, 1944). The figure in the present sample cannot be given. However, $85(8.3 \%)$ of the patients (15 officers, 70 other ranks) had a recurrence of infective hepatitis after leaving hospital at times varying from weeks to years (Table $I$ ). This high recurrence rate bears out our belief that one attack of infective hepatitis does not necessarily confer immunity from further attacks.

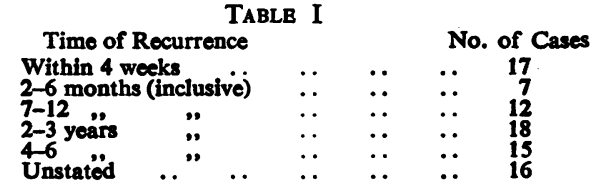

\section{Symptoms Following the Acute Attack}

It will be seen from Table II that approximately $26 \%$ felt $100 \%$ fit immediately after leaving hospital, $68 \%$ at the end of one month, $87 \%$ at the end of three months, and $95 \%$ at the end of one year.

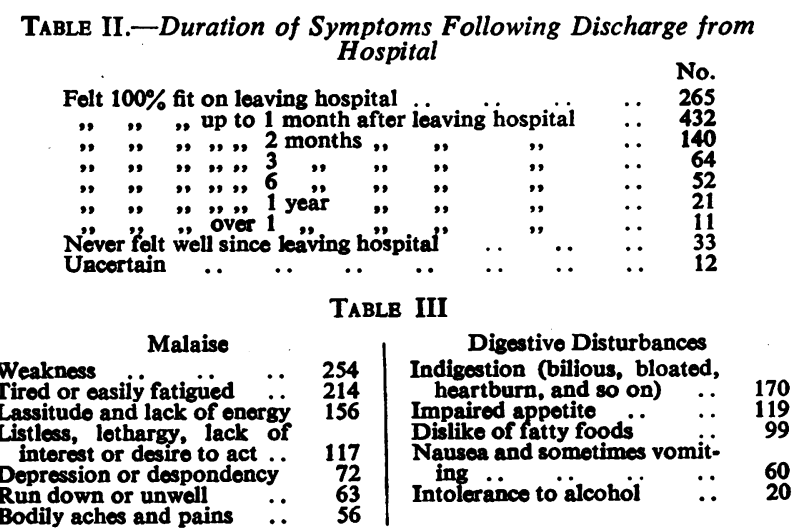

The total number of complaints described by the 765 men who had not felt $100 \%$ fit after leaving hospital was 1,691. The general pattern was one of malaise and digestive disturbance. The main complaints are shown in Table III. Some complaints were less frequent than might have been expected, such as further loss of weight (29), alteration of bowel habit (35), and persistent dark urine or yellow eyes (25).

\section{Prolonged Symptoms}

Seven years after the acute attack $33(3.2 \%)$ of the men stated that they had never felt $100 \%$ fit since the acute illness. Five of these had suffered a second attack from six months to six years after the first. Of those who had never felt well, 10 were officers and 23 other ranks. Their complaints are summarized, in order of frequency, as follows: periodic slight jaundice, 9 ; feeling of impending recurrence, 6 ; persistent lassitude, 6 ; intolerance to cooked fats, 5 ; repeated " bilious" attacks, 5 ; loss of appetite and nausea, 4 ; depression, 3 ; " never felt well," 3 ; " indigestion," 2 ; periodic discomfort over the liver, 2 ; intolerance to alcohol, 1 ; periodic vomiting, 1 ; " stomach never the same," 1.

These complaints dated only from the attack of infective hepatitis; in some they were slight and vague, whereas others undoubtedly had the so-called post-hepatitis syndrome. It is, of course just possible that the nine who complained of periodic slight jaundice-" My friends often say, "You have jaundice,' and I go real yellow," or, "Even now I still get a twinge in the same place and my eyes have a pale yellowish tint "-had continuing liver damage or subacute necrosis. If this was so the condition must have been very mild, as is borne out later in this report. How- ever, it is fruitless to analyse this group of 33 men further without having seen them, and it is intended that it shall be the subject of a further study. Here the important point to notice is the smallness of the group, which constitutes only $3.2 \%$ of the total replies, showing how the vast majority of men ultimately felt $100 \%$ fit after the acute attack.

\section{The Question of Cirrhosis}

It is known that some cases of infective hepatitis may progress to the stage of long-standing subacute necrosis of the liver with persistent or recurrent jaundice and that this in turn may finally result in the development of a condition indistinguishable pathologically from portal cirrhosis. Furthermore, it has been suspected that some patients with uncomplicated acute infective hepatitis may develop, years later, typical portal cirrhosis without any symptoms in the intervening years to suggest continued activity of liver disease.

In order to obtain an overall picture, and in an attempt to discover the incidence of such late developing complications, the follow-up was reopened in 1956. A further 132 men have now been traced, making a total of 1,184 , or $91.6 \%$ of the original sample.

Three more deaths as a result of accident and one from myocardial infarction were discovered (giving a total of 10 deaths from unrelated conditions and four from the acute episode of hepatitis at the time of the attack), but we have so far found no subsequent deaths as a result of chronic liver disease.

A study of the hospital records revealed no instances of subacute necrosis progressing to portal cirrhosis, but it seemed possible in 1949 that the nine men who had complained of periodic slight jaundice ever since their acute attack might be suffering from long-standing mild subacute necrosis of the liver. However, the small group of 33 men who complained in 1949 that they had never felt well after the initial illness were written to again in 1957 (15 years after the original attack). Not all have yet replied, but eight of the nine who had complained of continuing jaundice now state that they feel $100 \%$ fit, and only one of these men reports occasional slight yellowness, which makes it extremely unlikely that they have progressed to portal cirrhosis.

It is conceivable that some of the 1,052 men contacted in 1949 (most of whom have not yet been written to again) have since developed cirrhosis, or that there are examples in the 109 men it has not yet been possible to contact, but we have good reason to suppose that such is not the case.

The development of cirrhosis in an ex-Service man who had suffered from infective hepatitis during war service would constitute entitlement to a pension, while if the severity of the disease was sufficient to cause symptoms there is little doubt that under the present conditions of the Welfare State application for a pension would be made. With the assistance of Dr. H. B. F. Dixon, of the Ministry of Pensions, we have been able to study the records of all men with cirrhosis to whom entitlement has been granted between September 3, 1939, and September 30, 1957. In spite of the fact that an estimated 95,000 cases of infective hepatitis occurred among British troops during the second world war (Medical Statistical Branch of the War Office, 1958), the number of men pensioned for cirrhosis amounts to only 76 . As a result of a preliminary survey it appears that in only four instances was it possible that a single episode of uncomplicated infective hepatitis was followed years later by typical portal cirrhosis. None of the 1,293 men concerned in our follow-up have been pensioned for cirrhosis, and, although this does not prove that they have not developed it, we feel that it provides strong corroborative evidence that none have, in fact, done so. The follow-up continues.

\section{Summary}

A preliminary account is given of a long-term followup of 1,293 cases of infective hepatitis which occurred 
among British Forces in the Middle East in the second world war. So far $91.6 \%$ of the men have been contacted.

The mortality rate of the acute attack was $0.28 \%$, while the recurrence rate over the succeeding six years was $8.3 \%$.

The clinical features of the acute attack are briefly discussed and an account is given of the symptoms which complicated recovery.

In only $3.2 \%$ of cases did subsequent ill-health last as long as seven years.

No examples of subacute necrosis leading to cirrhosis occurred in this series, and to date no cases of later developing cirrhosis have been discovered.

A follow-up of this size was made possible only by the cooperation of many people. In particular, we wish to mention successive Directors-General of the Army Medical Services and the consultant physicians to the Army, the Statistical Branch of the Army Medical Department, many Army records offices, the Ministry of Pensions, the Registrar-General for England and Wales, the Registrar-General-for Scotland, the National Health Service Central Register Headquarters and Local Executive Councils, a large number of general practitioners, and the patients who wrote to us. We thank these and many others for their generous help. The secretarial expenses of the first part of the inquiry in 1949 were paid for by the Medical Research Council.

One of us (R. C. K.) held the Cooper and Coventson Research Scholarship, St. Bartholomew's Hospital. We also thank Mrs. Bartholomew, Miss Benson, Miss Knottenbelt, and Miss McCleland for their valuable secretarial help.

\section{REFERENCES}

Cullinan, E. R: (1943). Report to War Office (unpublished)

Cullinan, E. R: (1943). Report to War Office (unpublished). Medical

tion.
Spooner, E. T. C. (1943). No. 1 Medical Research Section M.E.F. (unpublished).

- (1944), Proc, roy. Soc. Med., 37, 171.

Wilson, C. (1944). Report to War Office (unpublished).

\section{A FACTUAL STUDY OF MALE HOMOSEXUALITY}

BY

R. E. HEMPHIL, M.D., D.P.M.

Medical Superintendent, Bristol Mental Hospitals, Bristol

A. LEITCH, M.D., D.P.M.

Consultant Psychiatrist, Bristol Mental Hospitals, Bristol

AND

J. R. STUART, M.B., D.P.M.

Deputy Medical Superintendent, Garlands Hospital, Carlisle (formerly of Bristol Mental Hospitals)

In 1948 the Home Office granted us permission to study some of the problems of homosexuality in prisoners at the open prison at Leyhill and at Horfield Prison, Bristol. The prisoners consented and were promised complete anonymity. Since some were serving long sentences we decided not to publish any results until some time after after all were released.

Homosexual tendencies are widespread in the ordinary population, but for many reasons it is impossible to ascertain their frequency and intensity or the many circumstances involved. Homosexuality can be defined only in a general way, and is often, and erroneously, regarded as identical with homosexual behaviour punishable by law. Since the latter results from strong homosexual tendencies it is among habitual homosexual offenders that the most pronounced forms of homosexuality are often to be found.
Leyhill, an open prison without bars, receives prisoners serving from three years upwards whose behaviour is good. Among them are some selected persistent homosexual offenders. Most are of good intelligence whose only connexion with the world of crime has been through homosexual practices. These subjects were ideal for study, as they were free from serious psychopathy yet unable to resist homosexual urges. Our case material was 64 men (56 at Leyhill and 8 at Horfield) aged from 20 to 61 , average 40.5 years : 43 had no previous convictions; 8 had one conviction for homosexual offences, 1 had two, and 1 had several; 9 had convictions for minor stealing and 2 for attempted suicide. Only 10 had served a prison sentence before.

We set out to investigate the somatic, endocrine, and psychological state and to see whether any of these modes of existence could be correlated with the sexual abnormality. We looked for elements common to the group by which homosexuality could be identified apart from active sexual behaviour and for the milestones in the development of the urge and in its establishment as a strong or even inevitable determinant in their social behaviour. The objects were explained to each prisoner. A few showed a natural reluctance to divulge information that might be disadvantageous to them, but confidence was soon gained, and we wish to record our appreciation of their frankness and desire to co-operate, although some had no more wish to be relieved of sexual drive than heterosexuals. A case history, according to a standard plan, was taken.

The meaning and significance of sexual feelings, intensity, constancy, and variability of the urge, the enduring or love attachments, the choice of age of partner, and the attitude to the opposite sex were fully discussed. Physical examination was made and deviations of body build and male secondary sex characteristics, effeminacy, and signs of endocrinopathy were looked for. Many were photographed for record, originally with the idea of somatotyping. This was later abandoned as of little value.

Hormone analysis on 48-hour urines was carried out in each case, but for technical reasons the results were regarded as reliable in only 49 . Seventeen prisoners, known to be not homosexual, of corresponding age and length of sentence, whose prison life resembled that of the subjects studied, agreed to act as controls. Their average age was 35 years, in the range 24 to 48 . For a variety of reasons complete data were either not available or were regarded as unreliable in some of the 64 , so that the totals are not the same for all investigations.

\section{Marital Status}

Forty of the men were single, 20 married, 3 divorced, and 1 was widowed. Kinsey et al. (1948) have emphasized the continuity of the gradations between exclusively heterosexual and exclusively homosexual behaviour. He evolved a seven-point scale for the estimation of degrees of homosexuality, the individual's place on the scale being determined by assessing the amount of overt homosexual experience and psychic reaction to sex factors. He made it clear that it is impossible to divide people into two categories, homosexual or heterosexual, since people show changes in their ratings on the heterosexual-homosexual scale or even change from exclusively heterosexual to exclusively homosexuál patterns, or vice versa. Kinsey ratings are : $0=$ exclusively heterosexual, no homosexual experience; $1=$ predominantly 